Technological University Dublin

DƯBLIN

ARROW@TU Dublin

2009-01-01

\title{
Optical Properties of Photopolymerisable Nanocomposites Containing Zeolite Nanoparticles
}

\author{
Izabela Naydenova \\ Technological University Dublin, izabela.naydenova@tudublin.ie \\ Tzvetanka Babeva \\ Technological University Dublin \\ Elsa Leite \\ Technological University Dublin
}

See next page for additional authors

Follow this and additional works at: https://arrow.tudublin.ie/cieocon2

Part of the Condensed Matter Physics Commons, and the Optics Commons

\section{Recommended Citation}

Naydenova, I., Babeva, T. \& Leite, E. (2009). Optical properties of photopolymerisable nanocomposites containing zeolite nanoparticles. Conference: Optical Data Storage Topical Meeting, (IEEE conferences), vol. ODS '09. pg. 84-86. doi:10.1109/ODS.2009.5031762

This Conference Paper is brought to you for free and open access by the Centre for Industrial and Engineering Optics at ARROW@TU Dublin. It has been accepted for inclusion in Conference Papers by an authorized administrator of ARROW@TU Dublin. For more information, please contact arrow.admin@tudublin.ie, aisling.coyne@tudublin.ie,gerard.connolly@tudublin.ie.

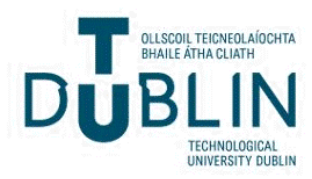




\section{Authors}

Izabela Naydenova, Tzvetanka Babeva, Elsa Leite, Nitesh Pandey, Temenujka Yovcheva, Svetlana Mintova, and Vincent Toal 
2009-01-01

\section{Optical Properties of Photopolymerisable Nanocomposites Containing Zeolite Nanoparticles}

Izabela Naydenova

Dublin Institute of Technology, izabela.naydenova@dit.ie

Tzvetanka Babeva

Dublin Institute of Technology

Elsa Leite

Dublin Institute of Technology

Nitesh Pandey

Dublin Institute of Technology

Temenujka Yovcheva

Plovdiv University

See next page for additional authors

\section{Recommended Citation}

Naydenova, I., Babeva, T., Leite, E., Pandey, N., Yovcheva, T., Mintova, S., et al. (2009). Optical properties of photopolymerisable nanocomposites containing zeolite nanoparticles. Proceedings of Optical Data Storage Topical Meeting, ODS 2009, 84-86.

This Conference Paper is brought to you for free and open access by the Centre for Industrial and Engineering Optics at ARROW@DIT. It has been accepted for inclusion in Articles by an authorized administrator of ARROW@DIT. For more information, please contact

yvonne.desmond@dit.ie, arrow.admin@dit.ie. 
Authors

Izabela Naydenova, Tzvetanka Babeva, Elsa Leite, Nitesh Pandey, Temenujka Yovcheva, Svetlana Mintova, and Vincent Toal 


\section{Optical properties of photopolymerisable nanocomposites containing zeolite nanoparticles}

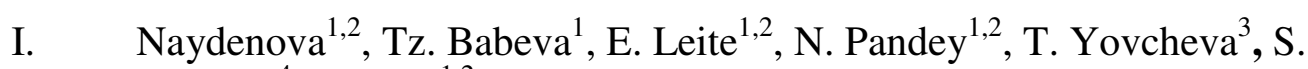
Mintova $^{4}$, V. Toal ${ }^{1,2}$

${ }^{1}$ Centre for Industrial and Engineering Optics, Dublin Institute of Technology, Kevin Street, Dublin 8, Ireland

${ }^{2}$ School of Physics, Faculty of Science, Dublin Institute of Technology, Kevin Street, Dublin 8, Ireland

${ }^{3}$ Plovdiv University, Department of Experimental Physics, 24 Tzar Assen str., 4000 Plovdiv, Bulgaria

${ }^{4}$ Laboratoire Catalyse \& Spectrochimie, University of Caen, 6, boulevard du Maréchal Juin, 14050 Caen Cedex, France

Acrylamide-based photopolymerisable nanocomposites containing three different types of nanozeolites - Si-MFI, AlPO and BEA, were studied. The influence of the porous nanoparticles on the average refractive index, optical scattering, holographic recording properties and shrinkage were characterised. 
The results from the optical characterisation of three different photopolymerisable nanocomposites are presented. Zeolite nanopartices were chosen as an inorganic additive for improving the dynamic range and shrinkage properties of an acrylamide based photopolymer developed at the Centre for Industrial and Engineering Optics at Dublin Institute of Technology [1-3]. In addition to improving the properties of the holographic recording material $[4,5]$ the inclusion of a porous nanocomponent and its spatial redistribution during the holographic recording process opens new horizons for the design and fabrication of holographic sensors [6].

The influence of Si-MFI, AlPO-18 and BEA nanozeolites on the nanocomposites optical properties was studied. The zeolite nanoparticles differ in their chemical composition and structure, hydrophobic/hydrophilic nature and pore size [7]. The choice of large-pore size nanoparticles (BEA) [8] and medium to small-pore size nanoparticles (Si-MFI and AlPO-18) [9,10] allows us to distinguish between two situations - when the acrylamide monomer molecules can be trapped inside the nanoparticles (BEA) and when they are larger than the nanoparticles' pore size ( $\mathrm{Si}$ MFI, AlPO-18). AlPO-18 nanoparticles are known for their hydrophilic nature and their ability to retain water molecules inside their pores unless heated above given temperature [10] while Si-MFI nanoparticles are understood to remain empty due to their hydrophobic nature [9]. The interaction of the nanoparticles with the host acrylamide photopolymer was studied by Raman spectroscopy of layers prepared from nanocomposites containing the three different types of nanoparticles.

Good compatibility of the zeolite nanoparticles with the host photopolymer was confirmed by Dynamic Light Scattering (DLS) studies performed before and after addition of the nanoparticles to the photopolymer solution. No sign of nanoparticle aggregation in the nanocomposite solution was observed from the DLS results. The concentration of the nanoparticles in the water dispersion did not exceed $5 \mathrm{w} / \mathrm{w} \%$ but due to the fact that the solvent (water) evaporated during layer preparation the ultimate nanoparticle concentration ranged from 1 to $15 \mathrm{w} / \mathrm{w} \%$ and from 5 to $50 \mathrm{v} / \mathrm{v}$ $\%$. The compatibility of the nanoparticles and the photopolymer components in the dry layers was also confirmed by the low level of optical scattering which was characterised and compared for the three different types of nanoparticles.

The change in the average refractive index in the volume of the nanocomposite layers due to addition of nanozeolites was determined by theoretical modelling of the spectroscopic measurements of their transmission and reflection coefficients. The change in the surface refractive index was studied by the method of the disappearing diffraction pattern using a three wavelength laser refractometer [11].

The influence of the nanoparticle size on the holographic recording properties was studied for Si-MFI nanoparticles with sizes 10, 40 and $60 \mathrm{~nm}$. These results are compared with those obtained using nanocomposites containing $40 \mathrm{~nm}$ BEA and 180 nm AlPO-18 nanoparticles. Holographic recording properties are reported for different recording intensities ranging from 1 to $20 \mathrm{~mW} / \mathrm{cm}^{2}$ and spatial frequencies ranging from 500 to $20001 / \mathrm{mm}$.

The spatial redistribution of the nanoparticles as a result of the holographic recording process was confirmed by both SEM-EDX and Raman spectroscopy studies. 
It was observed that the addition of zeolite nanoparticle leads to significant suppression of the shrinkage due to polymerisation. The extend of shrinkage was studied by recording slanted transmission holographic gratings and determining the shift of the angular Bragg selectivity curve from its original angular position.

\section{References:}

[1] S. Martin, C.A. Feely and V. Toal, "Holographic recording characteristics of an acrylamide-based photopolymer", Appl. Optics 36, 5757-5768, (1997).

[2] I. Naydenova, S. Martin, R. Jallapuram, R. Howard, V. Toal, "Investigations of the diffusion processes in self-processing acrylamide-based photopolymer system", Applied Optics, 43 (14), 2900, (2004).

[3] R. Jallapuram, I. Naydenova, S. Martin, R. Howard, V. Toal, "Raman spectroscopy for the characterization of polymerization rate in an acrylamide-based photopolymer", Applied Optics, 47(2), 206-212 (2008).

[4] I. Naydenova, H. Sherif, S. Mintova, S. Martin and V. Toal, "Holographic recording in nanoparticle-doped photopolymer", Proc. SPIE 6252, 625206.1 (2006).

[5] I. Naydenova, S. Mintova, S. Martin and V. Toal, nanocomposites for novel holographic applications, SPIE News, DOI: 10.1117/2.1200801.1010.

[6] I. Naydenova and V. Toal, "Nanoparticle doped photopolymers for holographic applications" in "Ordered porous solids", Elsevier, ISBN-13: 978-0-444-53189-6.

[7] L. Tosheva, V. Valtchev, "Nanozeolites: Synthesis, Crystallization Mechanism, and Applications", Chem. Mater., 17, 2494, (2005).

[8] S. Mintova, M. Reinelt, T. Metzger, J. Senker, T. Bein, "Pure silica BETA colloidal zeolite assembled in thin films", Chem. Commun. 3, 326 (2003).

[9] Eng-Poh Ng and S. Mintova, "Nanoporous materials with enhanced hydrophilicity and high water sorption capacity", Microporous and Mesoporous Materials 114, 1 (2008).

[10] H. van Heyden, S. Mintova and T. Bein, "AlPO-18 nanocrystals synthesized under microwave irradiation”, J. Mater. Chem., 16, 514-518 (2006).

[11] Sainov S Laser microrefractometer" Rev. Sci. Instr. 623106 (1991). 